\title{
Resistance to penicillin among the Streptococcus pneumoniae in Turkey
}

\section{To the Editor:}

Streptococcus pneumoniae is the most common micro-organism which causes respiratory tract diseases affecting all age groups. The increasing frequency of pneumococcal strains resistant to penicillin has been reported all over the world. The emergence of drug-resistant strains threatens to complicate the management of respiratory infections due to pneumococcus. Atatürk Chest Disease and Thoracic Surgery Centre is one of the biggest training hospitals for pulmonary disease in Turkey. Nine-thousand inpatients and 60,000 outpatients with respiratory diseases are treated every year. Bacteriological examinations of materials obtained from both settings can give important clues to clinicians dealing with respiratory infections. We evaluated antibiotic susceptibility patterns of $S$. pneumoniae strains isolated from respiratory specimens between January 1997December 1998 from our bacteriology laboratory. A total of 548 strains of $S$. pneumoniae were isolated from respiratory sites during this period. Identification was based on colony morphology, Gram stain characteristics and optochin susceptibility. The antibiotics studied were penicillin, amox-clavunat, tetracycline, erythromycin, trimethoprim-sulphamethoxazole, cefuroxime, ceftriaxone, ofloxacin, piperacillin, aztreonam. In vitro antibiotic susceptibility was performed by the disc diffusion method following the National Committee for Clinical Laboratory Standards (NCCLS) guidelines [1].

Low-level resistance to penicillin was found in 16 isolates $(3.03 \%)$ while no isolates had high-level resistance. Moreover, there was a decrease in sensitivity against macrolids $(73.6 \%)$ and to second generation sefalosporins $(78.7 \%)$ in our samples (table 1 ).

Table 1.-Antibiotic resistance pattern of Streptococcus pneumoniae strains isolated from respiratory sites

\begin{tabular}{lccc}
\hline Antibiotics & $\begin{array}{c}\text { Low-level } \\
\text { resistance } \%\end{array}$ & $\begin{array}{c}\text { High-level } \\
\text { resistance } \%\end{array}$ & $\begin{array}{c}\text { Susceptible } \\
\%\end{array}$ \\
\hline Penicillin & 3.0 & & 97.0 \\
Amox-clavunat & 1.8 & 0.9 & 97.3 \\
Trimethoprim- & 21.9 & 48.2 & 29.9 \\
$\quad$ sulphamethoxazole & & & \\
Erythromycin & 13.9 & 12.5 & 73.6 \\
Tetracyline & 48.9 & 8.9 & 42.2 \\
Cefuroxime & 10.5 & 10.8 & 78.7 \\
Ceftriaxone & 3.9 & 6.1 & 90.0 \\
Ofloxacin & 7.6 & 1.1 & 91.3 \\
Piperacillin & 8.0 & & 92.0 \\
Aztreonam & 18.5 & 25.9 & 55.6 \\
\hline
\end{tabular}

In other studies conducted in Turkey on the subject of examining penicillin resistance in pneumococcal infections, results were different according to the group and hospital examined. But in our study, the important part of the $S$. pneumoniae isolates $(93.6 \%)$ originated from sputum and the others $(6.4 \%)$ were bronchial lavage, tracheal aspirates and postnasal secretion. We believe that their resistance patterns are important for respiratory physicians when they are choosing empirical antibiotics for respiratory infections. In addition to this, we found that alternative antibiotics for $S$. pneumoniae tend to be more resistant than penicillin.

The first isolation of penicillin-resistant pneumococci was from Australia in 1967 [2] and New Guinea [3]. The similar strains became widespread in the world [4]. High-level penicillin-resistant pneumococci were reported in South Africa in 1977 [5]. This is the first report of penicillin resistance in Streptococcus pneumoniae isolated from respiratory sites in adults from Turkey. This study showed that penicillin is still an appropriate drug for respiratory infections caused by Streptococcus pneumoniae. All laboratories should be encouraged to record sensitivity to several antibiotics for use in their own areas so as to enable them to advise clinicians on the most appropriate antibiotics to use in the empirical treatment of infection.

A.S. Yurdakul ${ }^{*}$, H.C. Çalişir*, M. Atasever ${ }^{\#}$, L. Ordulu*, M. Öğretensoy*

*Depts of Pulmonology and ${ }^{\#}$ Bacteriology, Atatürk Chest Disease and Thoracic Surgery Centre, Ankara, Turkey.

\section{References}

1. National Committee for Clinical Laboratory Standards. Performance standards for antimicrobial disk susceptibility tests - fourth edition: Approved standard. NCCLS Document M2-A4. Villanova, Pa, NCCLS, 1990.

2. Hansman D, Bullen MM. A resistant pneumococcus. Lancet 1967; 2: 264-265.

3. Hansman D, Devitt L, Miles H, Riley I. Pneumococci relatively insensitivite to penicillin in Australia and New Guinea. Medical Journal of Australia 1974; 2: 353-356.

4. Appelbaum PC. Antimicrobial resistance in Streptococcus pneumoniae: An overview. Clin Infect Dis 1992 15: 77-83.

5. Appelbaum PC, Bhamjee A, Scragg JN, Hallett AF, Bowen AJ, Cooper RC. Streptococcus pneumoniae resistant to penicillin and chloramphenicol. Lancet 1977; 2: 995-997. 